\title{
Heavy rain events in the Western Mediterranean: an atmospheric pattern classification
}

\author{
C. Martínez, J. Campins, A. Jansà, and A. Genovés \\ Centro Meteorológico en Illes Balears, Instituto Nacional de Meteorología, Spain
}

Received: 20 December 2007 - Revised: 25 April 2008 - Accepted: 13 May 2008 - Published: 22 May 2008

\begin{abstract}
Heavy rain is one of the most important high-impact weather phenomena that occasionally affect Mediterranean areas. The aim of this study is to achieve a classification of atmospheric patterns related to heavy rain events in both French and Spanish Mediterranean regions. The classification is made on some atmospheric fields (geopotential at $1000 \mathrm{hPa}$ and at $500 \mathrm{hPa}$ and temperature at $850 \mathrm{hPa}$ ) of HIRLAM-INM- $0.5^{\circ}$ operational analysis, for heavy rain events included in the High Impact Weather MEDEX database. It covers a period of roughly 7 and a half years, from January 1997 to May 2004. A Principal Components Analysis was conducted to reduce the number of variables. After that, by means of a Cluster Analysis, the heavy rain events are classified into 8 atmospheric patterns. The results show a good relationship between regions affected by heavy rain and atmospheric patterns, in the sense that the same atmospheric patterns usually produce heavy rain in different regions, and heavy rain in different regions is usually due to specific atmospheric patterns.
\end{abstract}

\section{Introduction}

Although Western Mediterranean areas are usually wellknown for their pleasant weather, severe weather phenomena can occasionally affect these regions. Due to the particular topography of the area, with high mountains surrounding the Mediterranean Sea, heavy rain events can produce natural hazards, like flash-floods or landslides, with important consequences for human life.

The relationship between atmospheric patterns and precipitation has been widely studied for many regions in Europe (Trigo and DaCamara, 2000; Plaut et al., 2001; Esteban et al., 2005) and more specifically in the Mediterranean (Romero et al., 1999; Houssos and Bartzokas, 2006; Lana et al., 2007). From another point of view, the statistical relationship between heavy rain events and cyclones is studied in Jansà et al. (2001) and Campins et al. (2006).

This study forms part of the MEDEX project, whose main objective is to improve knowledge and the short-forecasting of the cyclones that produce high-impact weather in the Mediterranean (see http://medex.inm.uib.es). The specific purpose of the present study is to obtain an atmospheric pattern classification of a set of heavy rain events which affected the Spanish and the French Mediterranean regions.

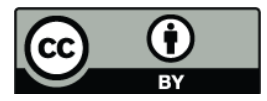

Correspondence to: C. Martínez (cristina.martinez@inm.es)

\section{Data and methodology}

The Heavy Rain (hereafter, HR) data comes from the MEDEX database for High-Impact Weather. The database contains the HR and strong wind data registered around the Mediterranean areas. For MEDEX, HR events are defined as ones in which at least $60 \mathrm{~mm}$ of precipitation are recorded at any meteorological stations in a pluviometric day $(24 \mathrm{~h}$, from 07:00 UTC of day D to 07:00 UTC of day D+1).

For this study, the Spanish and French Mediterranean regions are selected. For a 7-year period from January 1997 to May 2004, there are records at 5830 pluviometric stations. The regions are, in Spain, Eastern Andalusia (AOR), Aragon (ARN), the Balearic Islands (BAL), Castilla la Mancha (MCM), Catalonia (CAT), Murcia (MUR), and Valencia (VAL); in France, Corsica (CO), Cote-d'Azur (CA), Languedoc-Roussillon (LR), Eastern Midi-Pyrenees (MP), Provence-Alpes-Sud (PA), and Southern Rhone-Alpes (RA), (see Fig. 2 for an approximate location). Owing to the large area over which the stations are sited and the large number of records within the 7-year period, for this study a "HR event" is redefined as the one in which at least $60 \mathrm{~mm} / 24 \mathrm{~h}$ of precipitation is registered at 4 or more meteorological stations. According to the new definition, there are $472 \mathrm{HR}$ events, which means an average of $63 \mathrm{HR}$ events per year. The highest frequency of the events corresponds to autumn (39\% of all cases, see Table 1).

Published by Copernicus Publications. 

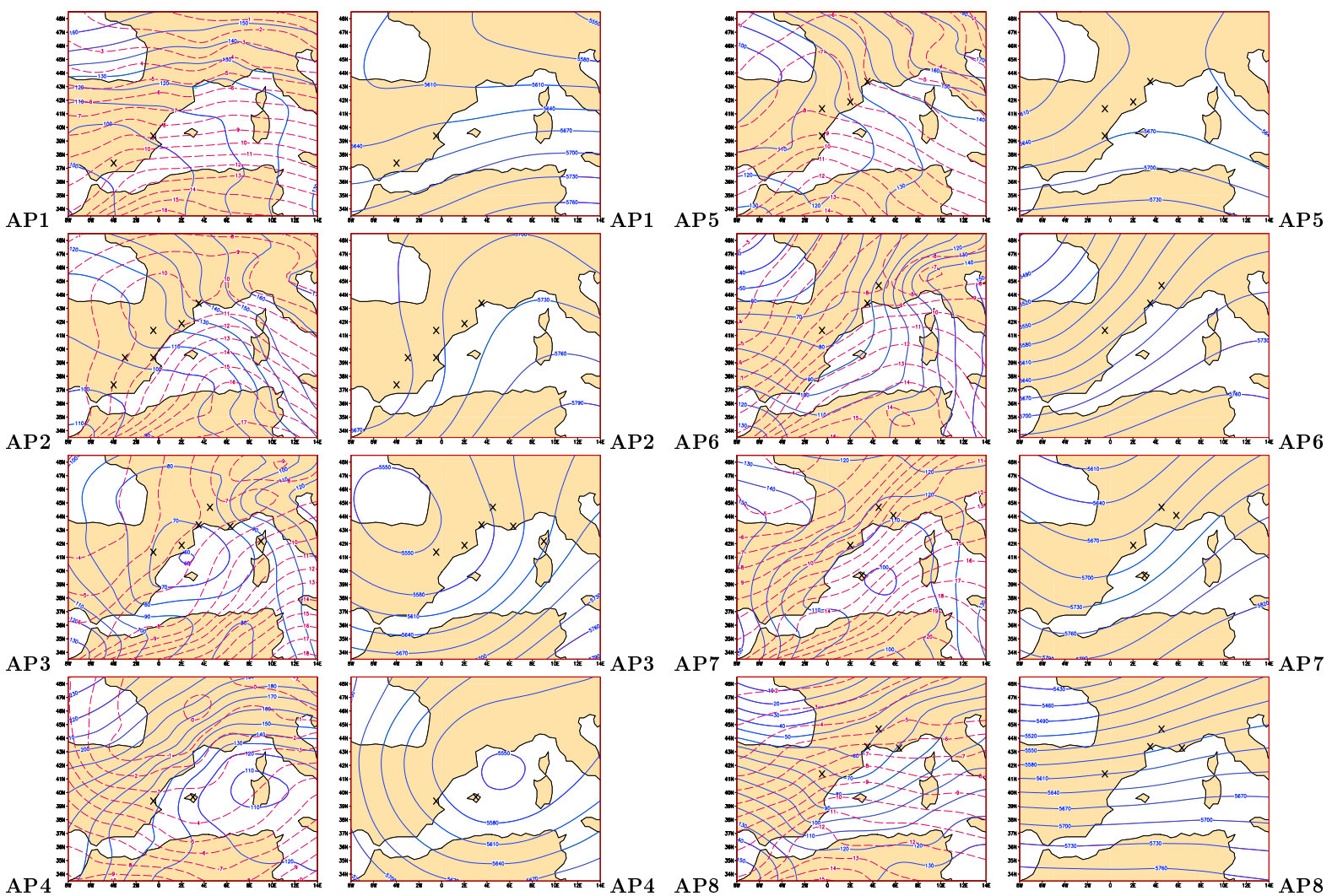

Figure 1. Averaged atmospheric fields for each AP. Panels with two fields: $\phi_{1000}$ (blue solid lines, $10 \mathrm{gpm}$ ) and $T_{850}$ (red dashed lines, $1^{\circ} \mathrm{C}$ ). Panels with one field: $\phi_{500}$ (blue solid lines, $30 \mathrm{gpm}$ ). Marked with a cross $(\mathrm{X})$ are the regions which were usually affected by HR (more than $30 \%$ of events) for each AP.

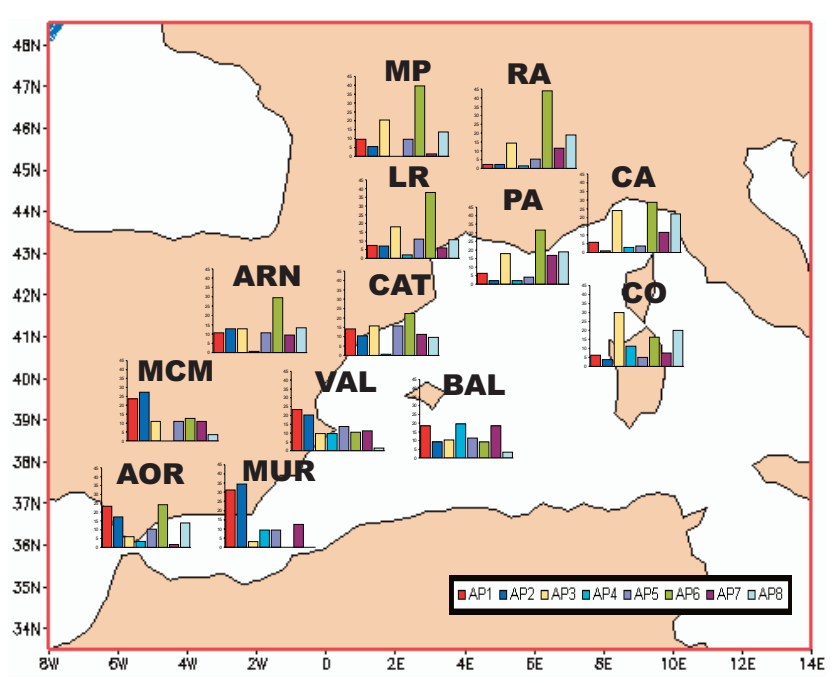

Figure 2. AP distribution (in percentage, with the y-axis scaled up to $45 \%$ ) for each region.
Table 1. Percentage of HR events per season for each AP and for the total set of events.

\begin{tabular}{ccccc}
\hline AP & Spring & Summer & Autumn & Winter \\
\hline AP1 & 23.9 & 17.9 & 32.8 & 25.4 \\
AP2 & 34.1 & 11.4 & 45.5 & 9.1 \\
AP3 & 45.2 & 21 & 21 & 12.9 \\
AP4 & 3.2 & 19.4 & 38.7 & 38.7 \\
AP5 & 7.7 & 9.6 & 44.2 & 38.5 \\
AP6 & 17.3 & 9.6 & 44.2 & 28.8 \\
AP7 & 10.6 & 40.4 & 42.6 & 6.4 \\
AP8 & 16.9 & 12.3 & 44.6 & 26.2 \\
\hline TOTAL & 20.8 & 16.5 & 39.2 & 23.5 \\
\hline
\end{tabular}

To obtain the atmospheric configuration that induces a HR event, the classification is made for the HR event day (hereafter, DHR) and also for the previous day (hereafter, DHR1). The atmospheric data fields that are used are the gridded analysis of geopotential at $1000 \mathrm{hPa}$ and at $500 \mathrm{hPa}$ and temperature at $850 \mathrm{hPa}$, (hereafter, $\phi_{1000}, \phi_{500}$ and $T_{850}$ ), from the HIRLAM-INM- $0.5^{\circ}$ operational analysis, smoothed by a Cressman Filter with $r_{0}=200 \mathrm{~km}$ (Cressman, 1959). 
It is considered that these fields can be used as an initial approach for a general view of the dynamical mechanisms of HR generation. To represent the atmospheric configuration for a day, the 12:00 UTC analysis is selected. The area where the research is made, is centered in the Western Mediterranean, and it extends over a domain placed between $33.5^{\circ} \mathrm{N}$ and $48.5^{\circ} \mathrm{N}$ latitude, and between $8^{\circ} \mathrm{W}$ and $14^{\circ} \mathrm{E}$ longitude, which implies 1395 grid points. In order to obtain the Atmospheric Pattern classification (hereafter, AP) a Principal Component Analysis (PCA) and a Cluster Analysis (CA) are made (Yarnal, 1993). First, the high number of variables is reduced by applying a PCA (Wilks, 1995) to each of the 6 T-mode (day-by-day) correlation matrixes (3 for DHR and 3 for DHR-1). For each matrix only the most important loadings are considered, that is, those that account for at least $90 \%$ of the total variance. Therefore, 6 components for the matrixes $\phi_{1000}$ and $T_{850}$ and 5 components for the $\phi_{500}$ ones are stored. After that, the CA is applied to the total matrix of loadings (34 loadings) of the 472 events. The CA classifies objects (events in this case) in groups whose elements are similar (in the sense of the loadings). That means that events with similar extracted loadings will be clustered together. The clustering algorithm used is the non-hierarchical k-means method (Andenberg, 1973). This algorithm minimizes the total within-cluster sum of squares (W). However, for this algorithm the number of groups (k) is unknown a priori, and it must be stated before the algorithm proceeds. So, taking into account that $\mathrm{W}$ decreases as $\mathrm{k}$ increases, in the present study the optimum number of groups is selected when the decrease in $\mathrm{W}$ is not significant ( $\mathrm{k}$ ranging from 2 to 20); this occurs when eight groups are selected.

\section{Results}

Eight Atmospheric Patterns are obtained (hereafter AP1, AP2,..., AP8). For each AP the mean fields are calculated by averaging the atmospheric fields corresponding to the events clustered in each AP. For the results description it is important to take into account two key points. Firstly, the APs do not represent real atmospheric situations, they are an average of actual events, and secondly, the classification is made for DHR and DHR-1 together. As the patterns that correspond to both days are very similar, only the DHR patterns are shown. The following is a general description of each AP (see Fig. 1 and Table 1).

AP1 (67 events) This is characterized by a low pressure center located to the southwest of the Iberian Peninsula at $1000 \mathrm{hPa}$ that induces a weak easterly flow towards the Spanish Mediterranean regions. At $500 \mathrm{hPa}$ a trough extends from Central Europe to the Atlantic. At $850 \mathrm{hPa}$ an intense temperature gradient with a warm advection can be noticed. The regions usually affected by HR are Valencia and Eastern Andalusia.
AP2 (44 events) At $1000 \mathrm{hPa}$ an intense southeasterly Mediterranean flow, also produced by a low located to the southwest of the Iberian Peninsula, affects most of the regions. At $500 \mathrm{hPa}$ a trough is situated over the west of the Iberian Peninsula. The temperature field at $850 \mathrm{hPa}$ shows an intense ridge over the Mediterranean, with a warm advection over almost all the regions. All the Spanish regions and Languedoc (France), are affected by the HR events. Most of these events occur in autumn and spring.

AP3 (62 events) There is a cyclonic structure between Catalonia and the Balearic Islands at $1000 \mathrm{hPa}$, and a cutoff westwards, at $500 \mathrm{hPa}$. This structure induces cold northerly flow over the Iberian Peninsula and wet and warm southerly flow over the French regions. Almost $50 \%$ of the events occur in spring. The regions most frequently affected are Languedoc, Cote d'Azur, Corsica and Southern RhoneAlpes, in France, and Catalonia and Aragon, in Spain.

AP4 (31 events) This pattern is the least frequent one. It shows a cyclonic structure over Sardinia with a cut-off low at $500 \mathrm{hPa}$ west of the $1000 \mathrm{hPa}$ cyclone. There is an intense northeasterly flow that produces a cold temperature advection. The Balearic Islands and Valencia are the regions most frequently affected by HR for this AP. Most of these events occur in winter and autumn.

AP5 (52 events) A pressure center to the west of the Iberian Peninsula, induces a warm, moist southerly flow over all the regions. At $850 \mathrm{hPa}$, a strong thermal ridge extends over the domain under consideration and at $500 \mathrm{hPa}$ there is a strong difluent flow over almost all the regions. Languedoc, Catalonia, Valencia and Aragon are the regions mostly affected by HR events. The events occur mainly in winter and autumn.

AP6 (104 events) This pattern is the most frequent one. A surface low pressure center, located to the northwest of France, affects all the regions, in particular with a warm and moist southerly Mediterranean flow over the French regions and the Balearics, and with a cold westerly flow over the Iberian Peninsula. At $500 \mathrm{hPa}$ the main feature is a trough. The regions affected by HR on most days are Rhone-Alpes, Aragon and specially Languedoc, with a significant $72 \%$ of days for this AP. Most of the HR days occur in autumn.

AP7 (47 events) At $1000 \mathrm{hPa}$ a weak cyclonic structure over the Balearic Islands can be noticed. This circulation generates a cold temperature advection in the western side of the domain (Spain), and a warm advection in the northeastern one (French regions). At $500 \mathrm{hPa}$ all the regions are under the influence of a trough, located over Spain. The temperature field shows an intense gradient. The highest frequency of events for this pattern occurs in autumn and summer. The Balearic Islands, Provence, Rhone-Alpes and Catalonia are the regions involved in most events.

AP8 (65 events) This shows almost zonal circulations at $1000 \mathrm{hPa}$ and $500 \mathrm{hPa}$ fields. It is probably characterized by the passage of cold fronts from Atlantic towards the Mediterranean. A weak coastal trough is reflected at $1000 \mathrm{hPa}$. 
The regions mostly affected by HR are Rhone-Alpes, Cote d'Azur, Languedoc and Aragon. A large percentage of these events take place in autumn.

\section{Discussion}

Depending on the $1000 \mathrm{hPa}$ flow (as derived from the $1000 \mathrm{hPa}$ geopotential pattern) and on the regions mostly affected by HR, the eight APs obtained above can be grouped in three main types. A different group of regions is affected by HR when a different variety of APs is shown.

The first AP type groups AP1, AP2 and AP5. In all of these patterns a low pressure centre is located to the SW or W of the Iberian Peninsula, outside the Mediterranean, and an easterly flow blows in the Western Mediterranean, carrying wet Mediterranean air against the eastern flanks of the Iberian Peninsula. These regions (Eastern Andalusia, Valencia, Catalonia) are the most frequently affected by HR when any AP of this group is presented. Within this type, when the low centre is located more to the south (AP1), the southern regions are more affected, and the contrary occurs when the low centre is located more to the north (AP5). AP2 is an intermediate situation.

The second AP type groups AP6 and AP8. For this group the main low centre is a large depression located far away, in the Atlantic, to the north (AP8) or to the northwest (AP6) of the Iberian Peninsula. The corresponding low-level flow within the Mediterranean is southerly, even southeasterly (AP6), or southwesterly, giving a wet Mediterranean air inflow largely in southern France, where HR can occur. Aragon (probably the Central Pyrenees) can also be affected by HR, probably due to Atlantic air feeding.

The third AP type groups AP3, AP4 and AP7. This group is characterised by the presence of a clear low pressure centre within the Mediterranean basin that encourages the existence of wet Mediterranean air flow or a marked convergence. The exact location of the Mediterranean low determines where these meteorological factors are presented. The French regions, northeastern Spain and the islands (the Balearics and Corsica) are the areas mostly affected by HR.

From another point of view, for every HR affected region, the relative frequency of each AP can be checked. Doing this (see Fig. 2), we find that when HR affects the inland French regions, the AP present is mainly AP6, followed by AP3 and AP8. When HR occurs in Catalonia or Aragon, the associated AP is also mainly AP6. When HR affects the SE Spanish regions (Eastern Andalusia, Valencia, Murcia and Castilla la Mancha), the most frequent APs are AP1 and AP2. When the area affected by HR is the Balearic Islands, the most frequent AP is AP4, followed by AP1 and AP7. This is congruent with the results obtained by Lana et al. (2007). In general, the results concerning the Spanish Mediterranean regions are consistent with those obtained by Romero et al.
(1999). Finally, when HR affects Corsica, the associated AP is mainly AP3.

\section{Conclusions}

Eight atmospheric patterns related to heavy rain events in the Spanish and French Mediterranean regions have been obtained. These atmospheric patterns have been derived from gridded analyses of geopotential at $1000 \mathrm{hPa}$ and $500 \mathrm{hPa}$ and temperature at $850 \mathrm{hPa}$. Each atmospheric pattern has been described and the corresponding regions most probably affected by heavy rain have been identified. Results show a good agreement between atmospheric fields and affected regions. Therefore, despite the fact that the atmospheric patterns represent averaged fields, they could be used as a valuable tool to forecast heavy rain events in such regions.

Edited by: F. Stel and D. B. Giaiotti

Reviewed by: two anonymous referees

\section{References}

Andenberg, M. R.: Cluster analysis for applications, Academic Press, New York, 359 pp., 1973.

Campins, J., Jansà, A., and Genovés, A.: Heavy rain and strong wind events and cyclones in the Balearics, Adv. Geosci., 7, 7377, 2006, http://www.adv-geosci.net/7/73/2006/.

Cressman, G. P.: An operational objective analysis system, Mon. Weather Rev., 87, 367-374, 1959.

Esteban, P., Jones, P. D., Martín-Vide, J., and Mases, M.: Atmospheric circulation patterns related to heavy snowfall days in Andorra, Pyrenees, Int. J. Climatol., 25, 319-329, 2005.

Houssos, E. and Bartzokas, A.: Extreme precipitations events in NW Greece, Adv. Geosci., 7, 91-96, 2006, http://www.adv-geosci.net/7/91/2006/.

Jansà, A., Genovés, A., Picornell, M. A., Campins, J., Riosalido, R., and Carretero, O.: Western Mediterranean cyclones and heavy rain. Part 2: Statistical approach, Meteorol. Appl. 8, 43-56, 2001.

Lana, A., Campins, J., Genovés, A., and Jansà, A.: Atmospheric patterns for heavy rain events in the Balearic Islands, Adv. Geosci., 12, 27-32, 2007, http://www.adv-geosci.net/12/27/2007/.

Plaut, G., Schuepbach, E., and Doctor, M.: Heavy precipitation events over a few Alpine sub-regions and the links with largescale circulations, 1971-1995, Climate Res., 17, 285-302, 2001.

Romero, R., Sumner, G., Ramis, C., and Genovés, A.: A classification of the atmospheric circulation patterns producing significant daily rainfall in the Spanish Mediterranean area, Int. J. Climatol., 19, 765-785, 1999.

Trigo, R. M. and DaCamara, C. C.: Circulation weather types and their influence on the precipitation regime in Portugal, Int. J. Climatol., 20, 1559-1581, 2000.

Wilks, D.: Statistical methods in the atmospheric sciences, Academic Press, New York, 1995.

Yarnal, B.: Synoptic climatology in environmental analysis, Belhaven Press, London, 1993. 